\title{
STANDARDS INTEGRATION IN E-LEARNING, SIMULATIONS, AND TECHNICAL MANUALS
}

\author{
Jeffrey A. KRINOCK
}

$\mathrm{D}$ istance Learning (DL), Computer Based Training (CBT) and e-Learning today encompass a broad range of technologies and teaching theories and practices, all of which are being aggressively explored by various groups, enterprises, industries and interests around the world. This huge arena of exploration involves incalculable combinations of technologies and learning theories. Where all of this will lead cannot be clearly projected, neither in terms of the technologies that will apply tomorrow, nor how the teaching methods encompassed and affected by those technologies will be shaped and altered.

Standards for E-learning, CBT and DL, of course, bring at least some degree of organization to this milieu. We have seen this in recent years, as when military leadership of various nations has pushed heavily for the use of the Sharable Content Object Reference Model (SCORM) in the development of Web-based learning content. No single standard, however, spans even a significant portion of the range of teaching and learning technologies in growing use. Even a cursory listing of today's computer and Web-based Training (WBT) technologies includes simulations, gaming, technologies for peer-to-peer and student-to-instructor communication (chat rooms, threaded discussions, white boards, virtual classrooms, instant messaging, etc.), Electronic Performance Support Systems (including Intelligent Tutoring Systems, job aids, and Interactive Electronic Technical Manuals), and of course ongoing research with the Semantic Web and the search and discovery technologies it necessarily spawns.

Standards covering these technologies include many areas of overlap and even, in some cases, standards appear to be in competition. Take the area of simulations as an example. In the last ten years or so, just prior to the emergence of the High Level Architecture as the simulation standard of choice, the US military focused on at least two other standards for simulations. This has led to a period in which those generating military simulations had to consider all three simulation standards. 
This brings us to a point at which making sense of standards, to include analyzing their areas of overlap, may be a necessary starting point for those participating in the development and deployment of e-Learning, CBT, or DL content. Since analyzing all the various standards would require volumes, we shall start by taking a look at three of the more widely employed standards: HLA, ${ }^{1}$ S1000D, ${ }^{2}$ and the SCORM. ${ }^{3}$

\section{A Closer Look}

Each of these three standards - the SCORM, HLA, and S1000D - targets different segments of learning technology. Table 1 lists both the source of each standard, and the general objective of its standardization.

Table 1. Distance learning, simulation, and interactive manuals standards

\begin{tabular}{|c|c|c|c|}
\hline Standard & $\begin{array}{c}\text { Original } \\
\text { Sponsoring } \\
\text { Agency }\end{array}$ & Sources of Contribution & Targeted Technology \\
\hline SCORM & $\begin{array}{l}\text { Office of the } \\
\text { Secretary of } \\
\text { Defense } \\
\text { (US OSD) }\end{array}$ & $\begin{array}{l}\text { Primary input comes from } \\
\text { segments of the e-Learning } \\
\text { industry such as authoring } \\
\text { tool vendors and Learning } \\
\text { Management System } \\
\text { vendors and academia. }\end{array}$ & $\begin{array}{l}\text { In general, e-Learning; the } \\
\text { types of computer (and } \\
\text { now, Web-based) training } \\
\text { materials typically covered } \\
\text { by Computer Based } \\
\text { Training (CBT) in recent } \\
\text { years. }\end{array}$ \\
\hline $\begin{array}{l}\text { High } \\
\text { Level } \\
\text { Archi- } \\
\text { tecture }\end{array}$ & $\begin{array}{l}\text { Defense } \\
\text { Modeling and } \\
\text { Simulation } \\
\text { Office (DMSO) }\end{array}$ & $\begin{array}{l}\text { Combination of US DoD } \\
\text { input (various military } \\
\text { services) and the industry } \\
\text { groups supporting them. }\end{array}$ & $\begin{array}{l}\text { Simulations, to include } \\
\text { complex military } \\
\text { simulations involving } \\
\text { multiple participants in } \\
\text { diverse locations. Can } \\
\text { include anything from a } \\
\text { simple desktop software } \\
\text { simulation to complex, full- } \\
\text { hydraulic-motion jet } \\
\text { aircraft simulators. }\end{array}$ \\
\hline S1000D & $\begin{array}{l}\text { European } \\
\text { Association of } \\
\text { Aerospace } \\
\text { Industries } \\
\text { (AECMA) }\end{array}$ & $\begin{array}{l}\text { Broadly based group of } \\
\text { both hardware vendors } \\
\text { (e.g., jet aircraft and naval } \\
\text { ship builders) and the } \\
\text { military services and } \\
\text { academic interests of } \\
\text { multiple nations. Started in } \\
\text { Europe, but is expanding } \\
\text { its scope of influence to } \\
\text { both Asia and the US. }\end{array}$ & $\begin{array}{l}\text { Interactive Electronic } \\
\text { Technical Manuals } \\
\text { (IETMs). These are the } \\
\text { follow-ons to paper-based } \\
\text { manuals in growing use for } \\
\text { support of everything from } \\
\text { microwave ovens to fighter } \\
\text { jets. }\end{array}$ \\
\hline
\end{tabular}


On the surface there may not appear to be much overlap among these three standards. After all, what does a technical manual for maintenance of a fighter jet have directly in common with a Web-based course on military aviation weather? Or what does a simulation-laden Computer Assisted Exercise (CAX) have in common with either fighter jet maintenance or military aviation weather? The answers to the above are slightly complex, but in some cases these are potentially crucial questions for those interested in using computer technology to its fullest potential in support of military training and general security preparedness.

In a recent interview, Tim Tate, director of the Advanced Distributed Learning initiative's Job Performance Technology Center (JPTC) discussed the issue of overlap between the SCORM and S1000D. ${ }^{4}$ When describing military training of jet pilots, for instance, he described certain aspects of it almost in terms of a "hierarchy" of information flow. Training content may be the desired end of the SCORM's standardization of e-Learning material, but the source material, the essential data around which the training is built, is usually technical data and specifications.

A use case involving military aviation provides a good example. A pilot contemplating a takeoff at heavy gross aircraft weight at a high elevation airport will need to call on extensive knowledge about what are known as Category I, Category II, and Category III takeoffs. The real-world decision the pilot faces in such a situation is critical in the event of the need to abort a takeoff. Depending on the category of the takeoff (Cat 1, II, or III), the decision to abort can mean the difference between sliding off the end of the runway into a fiery ball or a safe and uneventful roll to a stop on the runway. The decision involves knowledge of everything from aviation weather to aircraft aerodynamics to the basics of an individual aircraft's performance capabilities.

Specifically, a pilot facing a critical go/no-go decision for takeoff in marginal conditions is trained to consider at least the following:

- Aircraft acceleration abilities at various altitudes, gross weights, and runway conditions;

- Aircraft braking distance on dry, wet, and slush-covered runways;

- Rated aircraft capabilities in icing conditions, as applicable;

- Equipment assisting emergency stopping in addition to braking (such as engine reverse thrust and tail hooks).

The training a pilot needs regarding Category I, II, and III takeoffs is certainly a candidate for SCORM-conformant content - perhaps even Web-delivered training content. (Also likely, of course, is the possibility to use a computerized aircraft 
simulator to practice special procedures, such as dropping a tail hook if the end of a runway is approaching during an aborted takeoff.)

Tim Tate's point is that the bulk of the information involved in creating appropriate SCORM-conformant training content or simulations will likely come from technical specifications and data and the technical manuals the jet manufacturer created and delivered with the jet.

Fifteen years ago, when technical manuals were typically paper based, an instructional designer assembling CBT about Category I, II, and III takeoffs had a relatively straightforward path to negotiate; a Subject Matter Expert (SME), likely a pilot, would have been consulted. The SME in turn would have accessed and perhaps excerpted appropriate portions of paper-based manuals to supply to the instructional designer, whose job it would be to turn the technical information into useable chunks of instruction for inclusion in the CBT.

Technical manuals today introduce an entirely new twist into the CBT design scenario. Today's Interactive Electronic Technical Manuals (IETMs) are increasingly likely to integrate training material, in addition to their traditional coverage of technical data, charts, and operating procedures. In other words, yesterday's standalone CBT - considered to be a completely separate matter from the technical manual on which it was largely based-may now be a part of the electronic version of the technical manual itself.

\section{Standards, Functionality, and Potential Areas of Overlap}

Should standards such as the SCORM, S1000D, and HLA adjust to areas of overlap such as those just described? Those of us involved in building and disseminating standards for e-Learning, CBT, and DL are well aware that "simple" is usually "better." Generating the support of multiple stakeholders-many of whom have massive investments in existing content and development processes and platforms - is challenging even when the goals of standardization are relatively modest, as they were, for instance, for early versions of the SCORM.

Nonetheless, the Advanced Distributed Learning (ADL) initiative, creators and editors of the SCORM, has recently sought to secure a Memorandum of Understanding (MOU) with AECMA, creators and editors of S1000D. ADL has also for several years been meeting and talking with the Defense Modeling and Simulation Office (DMSO), creators and editors of HLA.

To better grasp the need for collaboration between standards bodies, let's return to our use case involving marginal-weather takeoffs. An Air Force squadron commander might be interested on a day-to-day basis in tracking and assessing the following: 
- Rates of successful sortie launch (normal conditions);

- Effects of weather on launch rates;

- Individual pilot decision-making abilities (charted in part, perhaps, by how many aborted takeoffs result in tail-hook stops).

To take our use case a step further, if our marginal weather conditions were embedded as part of a CAX, the following information might be of interest to a wing commander:

- Successful sortie launch rates by squadron;

- Overall effects of emergency stops (tail hooks, hot brakes) on wing-wide sortie launch rates, maintenance operations, and aircraft turnaround;

- Rates of no-go decisions and emergency stops, wing-wide, charted by aircraft type and squadron;

- Effects of pilot decision-making abilities, tracked by squadron.

In short, our marginal weather scenario involves at least two main categories of information: technical information (e.g., overall rates of aborted takeoffs and efficiency of aircraft turnaround procedures, compared from aircraft A to aircraft B) and human performance considerations.

In addition, feedback is required and useful at three different levels, as a minimum:

1. Individual pilot: Were takeoff decisions rushed in the face of poor weather? During aborted takeoffs, did the pilot apply the right procedure, and were procedures executed correctly?

2. Squadron commander: Do takeoff go/no go procedures make sense as applied? Are there performance discrepancies from flight-to-flight, and from aircraft type to aircraft type (depending on the makeup of the squadron)?

3. Wing commander: Were performance discrepancies of a technical, procedural, or human nature? (e.g., Do technical variations from aircraft type to aircraft type make a difference in sortie success rate? Do training and procedures accurately reflect technical considerations? How many aborted takeoffs and related lost sorties were due to poor decision making?) How do support aircraft (e.g., AWACS or tankers), when affected by marginal weather, impact overall mission success?

Table 2 sheds light on our three standard's abilities to meet these various needs. Clearly, the standards — even as they exist today — help all involved in our scenario.

For example, a pilot with LMS access could have available not only Air Forcespecific takeoff training, but might find additional information available from a sister service or even from the aviation training programs of allied services. If the LMS and 
relevant WBT were SCORM conformant, the pilot might both participate in training and also be assured of access to real-time reporting of his performance in any WBTembedded assessments, since assessment reporting is one of the areas standardized by the SCORM.

In addition, the pilot may find ready access to a wide variety of valuable technical information - perhaps online, or perhaps in his deployment kit. Did the pilot "take a cable" (i.e., have to use the jet's tail hook to stop) while deployed, leading to the need for technical details about tow vehicle compatibility at an unfamiliar airport? Maybe a CD-ROM (or DVD) full of deployment-related S1000D-conformant IETMs supplies all the information needed to the remote air base's aircraft launch teams and maintenance crews.

Similarly, squadron and wing commanders participating in HLA-based distributed simulations might learn valuable lessons about the impact of weather on tanker availability, and in turn, on go/no-go decisions for their own units. HLA standardization opens the door for wide participation of squadrons, wings, and ground support units in broadly distributed exercises and simulations. HLA data sharing opens the door for deeper assessment of synergistic effects of diverse units working together, at a fraction of the cost of bringing them physically together in an exercise deployment.

In short, our three standards, as they stand today, offer the foundation for a wide variety of computer and Net-based mission support, at a variety of levels.

But what about the limitations listed in Table 2? Without question, the groups responsible for each of our three standards are aware of these limitations. In some cases, direct efforts to address them are already underway.

Table 2. Strengths and limitations of the SCORM, S1000D, and HLA

\begin{tabular}{|l|l|l|l|}
\hline Standard & $\begin{array}{l}\text { Support } \\
\text { Orientation }\end{array}$ & Support Strengths & Limitations \\
\hline SCORM & $\begin{array}{l}\text { Human } \\
\text { Performance }\end{array}$ & $\begin{array}{l}\text { Simplifies and standardizes } \\
\text { assessment reporting features } \\
\text { of broad base of e-Learning } \\
\text { tools and devices. Clearly } \\
\text { identifies the Web and } \\
\text { Learning Management } \\
\text { Systems as the delivery mode } \\
\text { for training material. Provides } \\
\text { for content labeling and } \\
\text { packaging. }\end{array}$ & $\begin{array}{l}\text { Applies to individual } \\
\text { performance only. } \\
\text { Specifically targets only } \\
\text { traditional CBT/WBT. } \\
\text { Dependant on Web } \\
\text { browsers for both content } \\
\text { presentation and } \\
\text { performance assessment } \\
\text { reporting. }\end{array}$ \\
\hline
\end{tabular}




\begin{tabular}{|l|l|l|l|}
\hline S1000D & Technical & $\begin{array}{l}\text { Standardizes numerous } \\
\text { aspects of technical manual } \\
\text { presentation, to include } \\
\text { addressing some "look and } \\
\text { feel" issues. }\end{array}$ & $\begin{array}{l}\text { No embedded standard for } \\
\text { integrating SCORM- } \\
\text { conformant training. }\end{array}$ \\
\hline HLA & Mixed & $\begin{array}{l}\text { Provides integration of simple } \\
\text { to highly complex simulations } \\
\text { in a heavily distributed } \\
\text { environment. Enables broad } \\
\text { and deep data exchange } \\
\text { between all types of } \\
\text { computer-based and } \\
\text { computer-supported } \\
\text { simulations. }\end{array}$ & $\begin{array}{l}\text { So embedded standard for } \\
\text { assessment and reporting } \\
\text { (individual or group). }\end{array}$ \\
\hline
\end{tabular}

For instance, within the last year various working groups looked at combining SCORM's ability to assess individual performance with HLA's ability to exchange data between simulations. Immediate hurdles presented themselves; SCORM specifically mandates that LMSs launch SCORM-conformant content and track individual performance in the content's embedded interactions and assessments. A typical LMS, however, does not have the ability to launch, coordinate, and track performance within a widely distributed simulation. This issue raised many legitimate questions, such as which application or object should have simulation launch responsibility? The LMS? The Sharable Content Object (SCO) launched by the LMS? The simulation itself?

Also, when simulations are suspended, how is assessment reporting handled, and where is the simulation suspension data stored? Relatively simple simulations, such as the desktop flight of a PC-based flight simulator, may not overtax the data storage abilities of the SCORM data model. Even the simplest of military-style flight simulators, however, generate massive quantities of simulation state data when a flight or mission is suspended. The SCORM data model, as a potential vehicle for storing the simulation suspension data on an LMS, is immediately and convincingly overwhelmed.

In addition, distributed simulations supporting a wing (or larger units), as in our use case, would involve performance assessment of multiple individuals and groups (squadrons, flights, etc.). Today, the SCORM is not equipped to provide for group performance and assessment tracking, so even an integrated HLA/SCORM standard would not currently provide for standardized reporting of group performance. 


\section{Coordinated Standards - Use Case Revisited}

The point of this paper, however, and the reason for the ADL/AECMA MOU and ongoing collaboration between ADL and DMSO is that focusing on jointly derived solutions among the standards development organizations could lead to greatly expanded opportunities to enhance computer and Net-based mission support.

What if, for example, the SCORM and HLA had an established mechanism for data exchange - both at the individual assessment level currently covered by the SCORM and at the simulation-state level of interest in most HLA-based simulations? Then further expand our standards interoperability to include S1000D-based IETMs. What if an online technical manual could adjust levels of technical detail presented based on analysis of SCORM-based assessment results, or, conversely, recommend SCORM-based training material on the basis of technical topics researched within the IETM? Or what if an IETM could be integrated into an HLA-based aircraft simulator so that appropriate technical manuals - and perhaps even SCORM-based procedure training - could be presented according to the situational needs of various emergency and non-standard procedures being practiced?

If we return to our use case involving marginal weather and a CAX, the possibilities inherent in an integrated-standards environment become more evident. Individual pilots and maintenance and ground support crews, of course, always benefit from readily available technical information. Pilots seeking optimized flight training and mission readiness could undoubtedly benefit as well from simulations that adjust scenarios based on active tracking of their performance, both for individual sorties and on a multi-sortie basis.

Putting it all together-HLA/SCORM enabled simulations and S1000D/SCORM enabled technical manuals - opens quite a few opportunities within a training exercise. Deployed pilots and their ground support crews in need of technical information find themselves able to gain access to both the required technical data and job aid types of training material. Take a cable while deployed in your jet to a foreign base? The IETM in your deployment kit might enable ground crews unfamiliar with your aircraft to understand and perform certain procedures that today requires the time and expense of flying in specialized ground crews.

Wing commanders tracking year-to-year performance in an exercise, able to collect and collate individual and squadron-level simulator training and assessment trends, can suggest tweaks to training regimens and then observe the results of those adjustments. Perhaps the mission checkout programs in the wing's squadrons call for three emergency abort practice sorties, but exercises conducted in marginal weather indicate unacceptable levels of pilot error in go/no-go decisions and takeoff abort procedures. The wing commander, with access to SCORM-based assessment results 
from simulators, can prescribe changes to mission readiness training, and then track the results of those changes on anything from a daily to yearly basis.

\section{Next Steps}

So often the impetus for progress in standards building comes from either apparent cost savings or from the desire for ever-increasing centralized control of operations and training. That finding points of collaboration for HLA, the SCORM, and S1000D would provide or enable both of these is evident.

Gathering input from end-users is just as viable an approach, and just as likely to generate movement in the appropriate direction. What do pilots need to improve their understanding and execution of emergency procedures in simulators? Would pausing a simulation to review a five or ten minute training module enhance the efficacy of solo simulator rides? And what do ground crews need to help them efficiently turn around deployed aircraft? Would access to training embedded in IETMs enable crews to better respond to an expanded list of ground emergencies and unusual situations?

Needless to say, the possibilities opened by coordinating standards apply to far more than aviation. Technical manuals and Web-based training now effectively cover the globe. Simulations, covering as they do the most expensive of real-world operations and equipment, are growing in pervasiveness and usefulness each year as well. To unleash the effectiveness of coordinated standards, command-level input, user-level input, and the best ideas and dreams of the technical and advisory teams behind each of the three standards bodies should be brought together soon and significantly. MOUs are a start; joint projects based on meeting real-world training and operations needs are an even better beginning. 


\section{Notes:}

$1 \mathrm{https}: / /$ www.dmso.mil/public/transition/hla/

2 http://www.s1000d.org/

3 http://www.adlnet.org/index.cfm?fuseaction=scormabt

4 Tim Tate, "Standards Status," Job Performance Action Team (JPAT) Meeting (Alexandria, VA: 20 February 2004).

JEFF KRINOCK is the Army Medical Department (AMEDD) program manager for MountainTop Technologies Incorporated, in Johnstown, PA, a recognized leader in e-learning technology and organizational development. In his current capacity he works with Temple University Medical School (Philadelphia, PA) in developing SCORM-conformant emergency medical response courseware in support of various topics related to homeland security. Mr. Krinock earned a Bachelor of Arts degree in Biblical Literature from Oral Roberts University and a Masters degree in Human Relations from the University of Oklahoma at Ramstein, Germany. He has completed additional graduate and post-graduate level work at a variety of schools to include the University of Boston, Ramstein, Germany, Oklahoma State University, and Eastern New Mexico University.

A former U.S. Air Force helicopter and fighter pilot, Mr. Krinock has worked in the computer and e-learning fields in various capacities for over 15 years. Most recently he spent more than three years as a member of the Advanced Distributed Learning (ADL) Technical Team, during which time he was a contributing editor to three versions of the Sharable Content Object Reference Model (SCORM), and the author or co-author of several reports, studies, and application guidelines published by the ADL initiative. He continues to write and lecture about SCORM and e-learning related topics to U.S. and international audiences. He is an active participant in ADL and the MedBiquitous Consortium. His research interests include distance learning in general and the relationship between and impact of digitally based job performance aids and human relations. E-mail: krinj@wmconnect.com. 